\title{
Organometallic carboxylate resists for extreme ultraviolet with high sensitivity
}

\author{
James Passarelli, ${ }^{a}$ Michael Murphy, ${ }^{a}$ Ryan Del Re, ${ }^{a}$ Miriam Sortland, ${ }^{a}$ Jodi Hotalen, ${ }^{a}$ Levi Dousharm, ${ }^{a}$ Roberto Fallica, ${ }^{b}$ \\ Yasin Ekinci, ${ }^{\mathrm{b}}$ Mark Neisser, ${ }^{\mathrm{c}}$ Daniel A. Freedman, ${ }^{\mathrm{d}}$ and Robert L. Brainard ${ }^{\mathrm{a}}$ 网 \\ a State University of New York Polytechnic Institute, Colleges of Nanoscale Science and Engineering, 257 Fuller Road, Albany, New York 12203, \\ United States \\ ${ }^{\mathrm{b}} \mathrm{Paul}$ Scherrer Institute, Villigen, Switzerland \\ 'Sematech, Albany, New York 12203, United States \\ ${ }^{\mathrm{d}}$ State University of New York, Department of Chemistry, 1 Hawk Drive, New Paltz, New York 12561, United States
}

\begin{abstract}
We have developed organometallic carboxylate compounds $\left[\mathrm{R}_{n} \mathrm{M}\left(\mathrm{O}_{2} \mathrm{CR}^{\prime}\right)_{2}\right]$ capable of acting as negative-tone extreme ultraviolet (EUV) resists. The most sensitive of these resists contain antimony, three R-groups and two carboxylate groups, and carboxylate groups with polymerizable olefins (e.g., acrylate, methacrylate, or styrenecarboxylate). Evidence suggests that high sensitivity is achieved through the polymerization of olefins in the exposed region. We have performed a systematic sensitivity study of the molecules of the type $\mathrm{R}_{n} \mathrm{M}\left(\mathrm{O}_{2} \mathrm{CR}^{\prime}\right)_{2}$ where we have studied seven $\mathrm{R}$ groups, four main group metals $(\mathrm{M})$, and three polymerizable carboxylate groups $\left(\mathrm{O}_{2} \mathrm{CR}^{\prime}\right)$. The sensitivity of these resists was evaluated using $E_{\max }$ or dose to maximum resist thickness after exposure and development. We found that the greatest predictor of sensitivity of the $\mathrm{R}_{n} \mathrm{Sb}\left(\mathrm{O}_{2} \mathrm{CR}^{\prime}\right)_{2}$ resists is their level of polymerizable olefins. We mathematically define the polymerizable olefin loading (POL) as the ratio of the number of olefins versus the number of nonhydrogen atoms. Linear and log plots of $E_{\max }$ versus POL for a variety of molecules of the type $\mathrm{R}_{3} \mathrm{Sb}\left(\mathrm{O}_{2} \mathrm{CR}^{\prime}\right)_{2}$ lend insight into the behavior of these

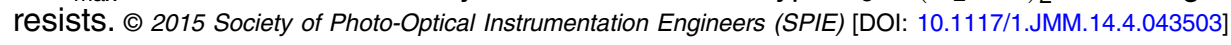

Keywords: extreme ultraviolet; organometallic; resist; molecular organometallic resists for extreme ultraviolet; antimony; olefin; high sensitivity.

Paper 15100P received Jun. 16, 2015; accepted for publication Sep. 10, 2015; published online Oct. 14, 2015.

\section{Introduction}

As the microelectronics industry follows Moore's law, the requirements for photoresists continue to increase. With 16-nm gatelengths in production, technology capable of supporting the 10-nm lithography node must be developed today. Extreme ultraviolet (EUV, $13.5 \mathrm{~nm}$ ) lithography is thought to be the next imaging technology for fabricating microelectronic devices, but there are still many obstacles that must be overcome. The traditional, chemically amplified photoresist systems, which have been successful in lithography since the 1980s, are encountering hurdles that are proving difficult $\mathbb{q}^{\mathrm{a}}$ to overcome, including poor photon absorption in thin films, ${ }^{\mathbb{Q}}$ moderate etch selectivity, and limited gains in resolution.

Recently, two novel resist systems have been developed based on metal-oxide thin films ${ }^{\mathbf{Q}}$ Researchers at Inpria Co. have printed $8-\mathrm{nm}$ dense lines with a dose of $200 \mathrm{~mJ} / \mathrm{cm}^{2}$ using metal-oxide resists. Christopher Ober's group at Cornell demonstrated 36-nm dense line patterning with a dose of $12 \mathrm{~mJ} / \mathrm{cm}^{2}$ using a resist composed of hafnium oxide nanoparticles. This pioneering work has demonstrated the great potential of inorganic systems as photoresists.

Here, we present a new design for EUV resists based on organometallic carboxylates of main-group elements. This work is a subset of our group's larger program, molecular organometallic resists for EUV (MORE). The MORE approach utilizes high EUV optical density metals to increase

*Address all correspondence to: Robert L. Brainard, E-mail: rbrainard@ sunycnse.com the photon absorbance of thin resist films. James Thackeray in his 2011 SPIE plenary presentation stated that the target absorption for EUV resist films is $50 \%$. To print 10 -nm lines with an aspect ratio of $2: 1$, film thickness must be around $20 \mathrm{~nm}$. Polyhydroxystyrene at this thickness will stop only $\sim 10 \%$ of the light $(T \sim 0.90)$ Loading organic polymers with fluorine will have limited impact. Teflon, which likely contains the most fluorine of any organic polymer, only stops $\sim 30 \%$ of the light in a film of $20 \mathrm{~nm}(T \sim 0.70)$ A continuous, 20-nm film of $\mathrm{HfO}_{2}$, on the other hand, will stop $\sim 50 \%$ of the EUV light?

In this work, we describe a set of organometallic carboxylate MORE resists that have displayed excellent sensitivities. These resists are of the general form $\mathrm{R}_{n} \mathrm{M}\left(\mathrm{O}_{2} \mathrm{CR}^{\prime}\right)_{2}$, where $\mathrm{M}$ is the main-group metal antimony, tin, tellurium or bismuth, and the carboxylate group is capable of undergoing free radical polymerization (acrylate, methacrylate, or styrene carboxylate). In this work, we explore the systematic variations of the metal $(\mathrm{M})$, the aliphatic or aromatic $\mathrm{R}$ group, and the polymerizable carboxylate group $\left(\mathrm{O}_{2} \mathrm{CR}^{\prime}\right)$.

\section{Results and Discussion}

In designing this resist platform, we sought a MORE resist where one photochemical reaction could lead to multiple solubility changing events. Our first attempt at an amplified MORE resist was through the utilization of photoinitiated free-radical polymerization. In this way, one initiation event could lead to multiple solubility-changing polymerization events and yield a negative-tone resist with good

\footnotetext{
$1932-5150 / 2015 / \$ 25.00$ @ 2015 SPIE
} 

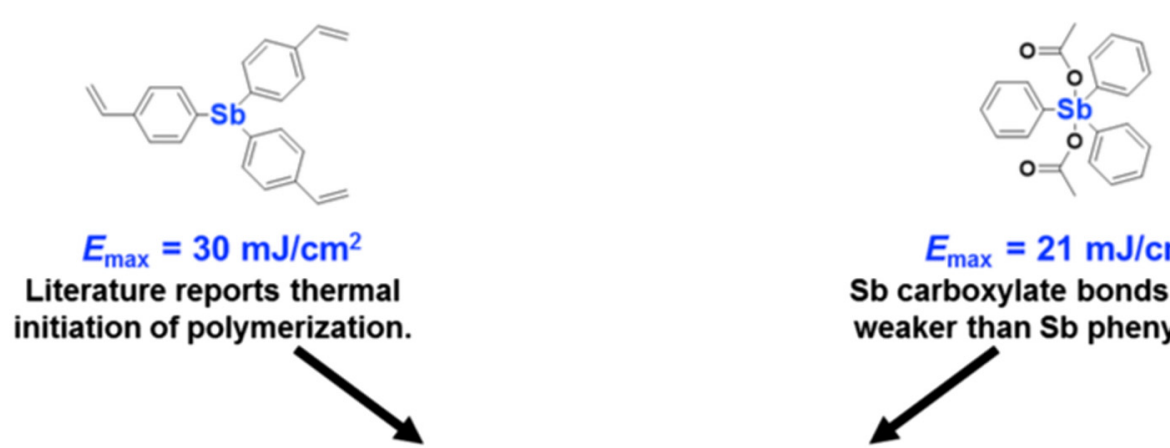

$E_{\max }=21 \mathrm{~mJ} / \mathrm{cm}^{2}$

Sb carboxylate bonds reported weaker than Sb phenyl bonds.

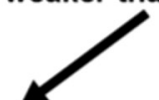

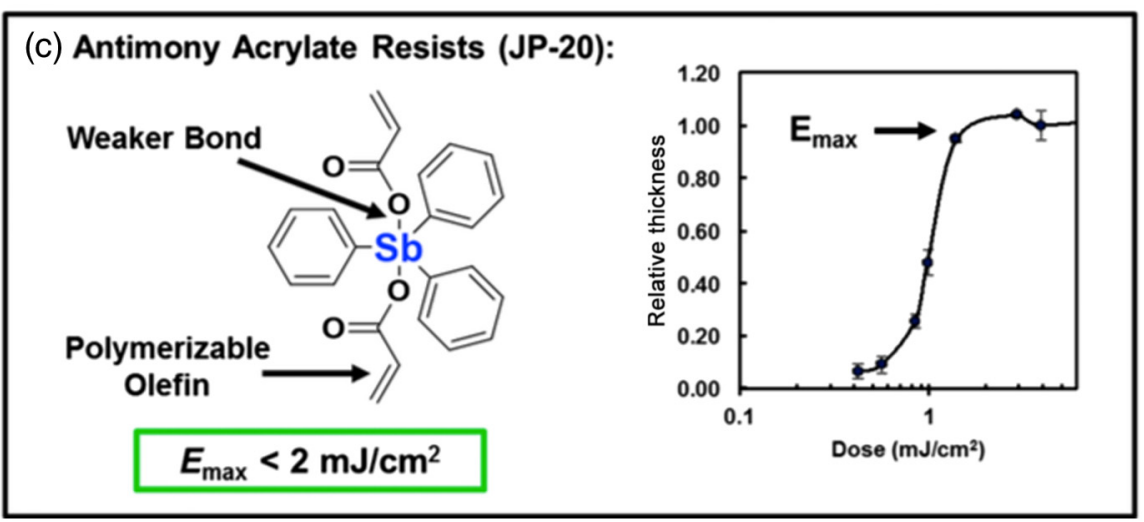

Fig. 1 System design of antimony organometallic carboxylate resist platform, JP-20. High sensitivity is achieved through the integration of two resist architectures, one that contains a polymerizable olefin and one that contains a bond that is more readily cleaved by EUV photons. (a) Tristyrene antimony (JP-12), (b) triphenylantimony diacetate (JP-18), and (c) antimony acrylate resists (JP-20).

sensitivity. Our first attempt at a free radical MORE resist was tri(styrene)antimony [Fig. 1(a)]. This molecule can undergo free radical polymerization when heated at $100^{\circ} \mathrm{C}$ and the result is a cross-linked and insoluble network. When we evaluated tri(styrene)antimony for its EUV sensitivity, we found that it was relatively insensitive. The $E_{\max }$ (dose to maximum thickness) was $30 \mathrm{~mJ} / \mathrm{cm}^{2}$. We attribute this insensitivity to the relatively high bond dissociation energy of a Ph-H bond, which is often proportional to the organometallic bond strength.

We have also investigated antimony organometallic carboxylate molecules that do not contain polymerizable olefins like tri(phenyl)antimony diacetate [Fig. [1(b)]. This molecule demonstrated improved sensitivities over tri(styrene)antimony $\left(E_{\max }=21 \mathrm{~mJ} / \mathrm{cm}^{2}\right)$. We attribute the improvement in sensitivity to the comparatively low bond dissociation energy of carboxylate peroxides, which is often proportional to organometallic bond strength. Excellent sensitivities $\left(E_{\max }<2 \mathrm{~mJ} / \mathrm{cm}^{2}\right)$ were achieved through the combination of these two previous structural features. Our first molecule of this new class was triphenylantimony diacrylate [JP-20, Fig. 1(c)]. This molecule contains both a polymerizable olefin as well as a relatively weak antimonycarboxylate bond.

Tri(phenyl)antimony diacrylate (JP-20) has demonstrated remarkable sensitivity characteristics of $E_{\text {size }}=5.6 \mathrm{~mJ} / \mathrm{cm}^{2}$ for $35 \mathrm{~nm} \mathrm{L/S}$ features (Fig. 2). Pattern modulation is also shown down to $16 \mathrm{~nm}$ although pattern collapse occurs at this resolution. This resist has also passed witness plate-based outgassing tests and has excellent shelf-life (no change to NMR of resist in solution for 6 weeks).

We propose that the sensitivity of this resist is due to the free radical polymerization of olefins in the exposed regions. We have tested this hypothesis by comparing the sensitivity of triphenylantimony diacrylate (JP-20) to triphenylantimony diacetate (JP-18, Fig. B). The sensitivity of the polymerizable acrylate is more than an order of magnitude greater

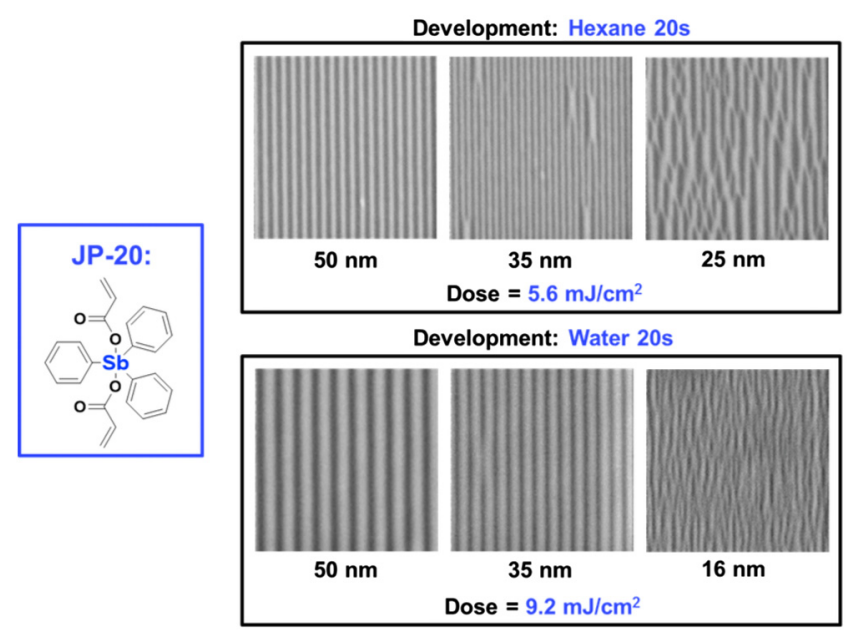

Fig. 2 Lithographic performance of JP-20 is a representative molecule of this resist platform. High sensitivity at moderate resolutions is demonstrated. Ultimate resolution is limited by pattern collapse. 


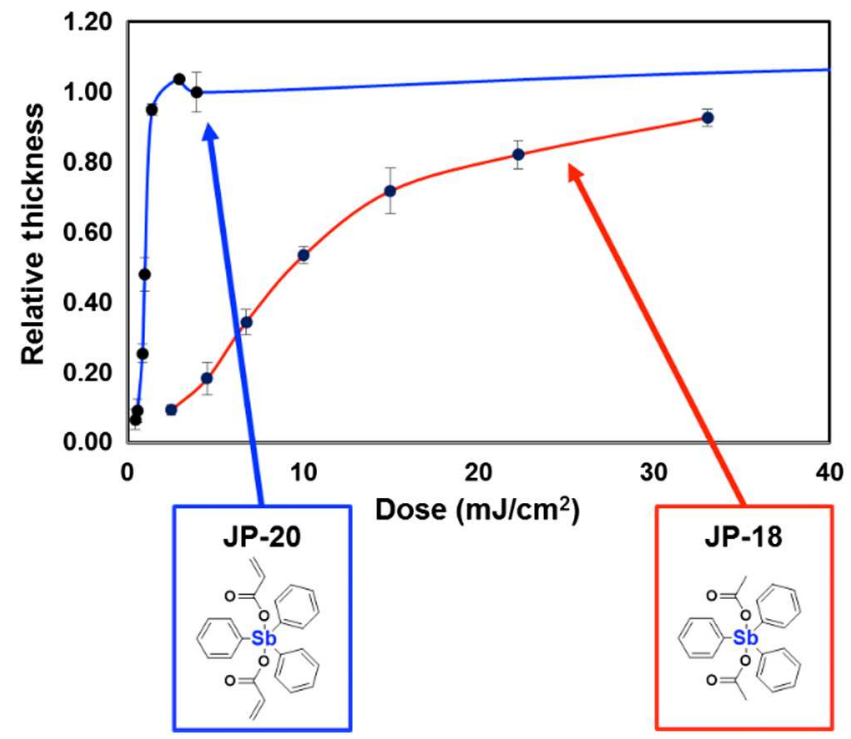

Fig. 3 Comparison of MORE resists JP-18 and JP-20. These two resists are composed of the same metal in the same oxidation state with largely the same chemical substituents. Slight modification between these resists results in dramatic improvement in photoresponse.

than the nonpolymerizable acetate group. Dissolution selectivity and contrast are also improved for the acrylate group. This evidence supports a free radical polymerization mechanism and we are attempting to confirm such a mechanism through spectroscopic means.

Our work details a systematic study of resists of the general form $\mathrm{R}_{n} \mathrm{M}\left(\mathrm{O}_{2} \mathrm{CR}^{\prime}\right)_{2}$ in which one of the ligands is capable of undergoing free radical polymerization. Specifically, we have carried out three studies, where we (1) vary metal composition in molecules of the type $\mathrm{Ph}_{n} \mathrm{M}$ (acrylate) ${ }_{2}$, (2) vary carboxylate composition in molecules of the type $\mathrm{Ph}_{3} \mathrm{Sb}\left(\mathrm{O}_{2} \mathrm{CR}^{\prime}\right)_{2}$, and (3) vary $\mathrm{R}$ composition in molecules of the type $\mathrm{R}_{3} \mathrm{Sb}\left(\mathrm{O}_{2} \mathrm{CR}^{\prime}\right)_{2}$.

\subsection{Effect of Metal Nuclei on the Sensitivity of $\mathrm{Ph}_{n} \mathrm{M}(\text { Acrylate })_{2}$}

All MORE photoresists contain at least one metal atom with high EUV optical density. The goal of this study is to compare the sensitivity of resists containing antimony, tin, tellurium, or bismuth. Molecules of the type $\mathrm{Ph}_{n} \mathrm{M}$ (acrylate $)_{2}$ were synthesized, coated, and evaluated for contrast-curve performance (Fig. (1). The relative sensitivities are antimony that produces the fastest resist, then bismuth $=$ tin, and tellurium is the slowest. This sensitivity trend cannot be explained by optical density differences since tin and tellurium are about the same and darkest, then antimony, followed by bismuth. The sensitivity of these resists is, therefore, not merely due to their ability to absorb photons but also due to other factors that will be explored in this paper.

\subsection{Effect of the Polymerizable Carboxylate Group of $\mathrm{Ph}_{3} \mathrm{Sb}\left(\mathrm{O}_{2} \mathrm{CR}^{\prime}\right)_{2}$ on Sensitivity}

Three typical monomers for free radical polymerization are acrylate, methacrylate, and styrene. In order to test the effect of these polymerizable carboxylate groups on sensitivity, we synthesized molecules of the general form $\mathrm{Ph}_{3} \mathrm{Sb}\left(\mathrm{O}_{2} \mathrm{CR}^{\prime}\right)_{2}$,

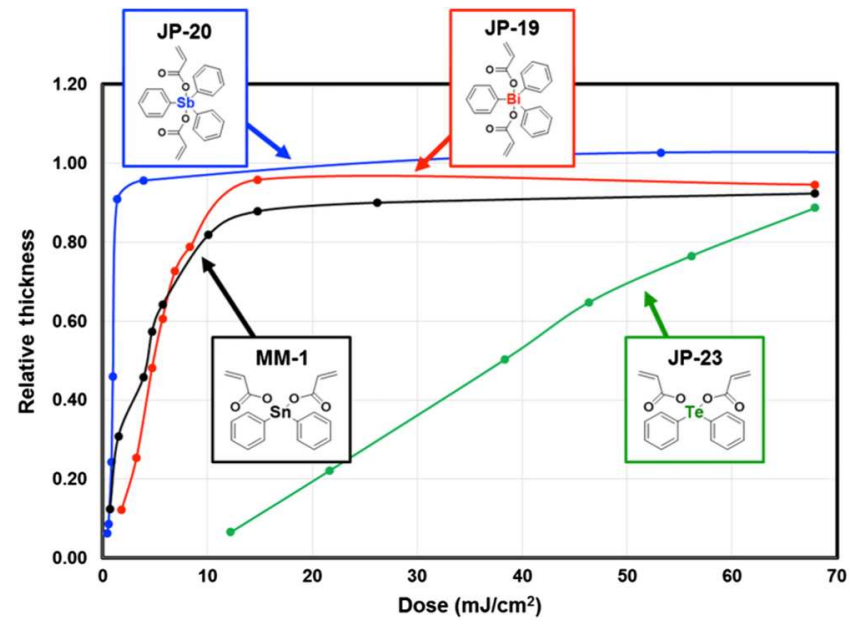

Fig. 4 Comparison of $\mathrm{Ph}_{n} \mathrm{M}(\text { acrylate })_{2}$, where $\mathrm{M}=$ antimony, bismuth, tin, or tellurium. Antimony is the most sensitive.

where the carboxylate was acrylate, methacrylate, or styrenecarboxylate. These three molecules were also compared to $\mathrm{Ph}_{3} \mathrm{Sb}(\mathrm{OAc})_{2}$, which does not contain a polymerizable group (Fig. 5).

The acrylate variant is more sensitive than methacrylate, which is more sensitive than styrenecarboxylate. These three polymerizable carboxylates all exhibited higher sensitivity than $\mathrm{Ph}_{3} \mathrm{Sb}(\mathrm{OAc})_{2}$. This sensitivity trend seems to scale with the molecular weight of the carboxylate group. A possible explanation for this is given in Sec. 2.4.

Lithographic evaluation of the three polymerizable carboxylates is shown in Fig. 6. Notice that patterning for the acrylate (JP-20) and methacrylate (JP-21) variant is achieved with $<7 \mathrm{~mJ} / \mathrm{cm}^{2}$, whereas the styrenecarboxylate (JP-30) is more than two times slower. Resolution and overall imaging characteristics for JP-30 are significantly improved over JP-20 and the dose is still respectable.

\subsection{Effect of the $R$ Group of $\mathrm{R}_{2} \mathrm{Sb}\left(\mathrm{O}_{2} C R^{\prime}\right)_{2}$ on Sensitivity}

The last and most extensive of the three molecular studies examines the effect of the hydrocarbon group on resist performance (Fig. 7). The selection of the hydrocarbon groups studied in this section is based on (1) exploring a variety of antimony-carbon bond types, such as antimony-aromatic and antimony-aliphatic bonds, and (2) modulating resist film properties, such as solubility and film crystallinity. Notice that these resists are characterized by excellent sensitivity. Several resists are capable of patterning below 30-nm dense lines although pattern collapse occurs at these smaller dimensions.

In analysis of the lithographic results of this diverse resist set, we have observed trends in scanning electron microscope (SEM) stability as well as several unexpected phenomena. These are detailed below in Secs. 2.3.1 and 2.3.2, respectively.

\subsubsection{Effect of the $R$ Group of $\mathrm{R}_{3} \mathrm{Sb}\left(\mathrm{O}_{2} \mathrm{CR}\right)_{2}$ on sensitivity-SEM stability trends}

The first antimony organometallic carboxylate molecule of interest, JP-20, can only withstand one SEM scan before being destroyed (Fig. 8). Pattern modulation is observed in the first scan while no pattern modulation is observed 


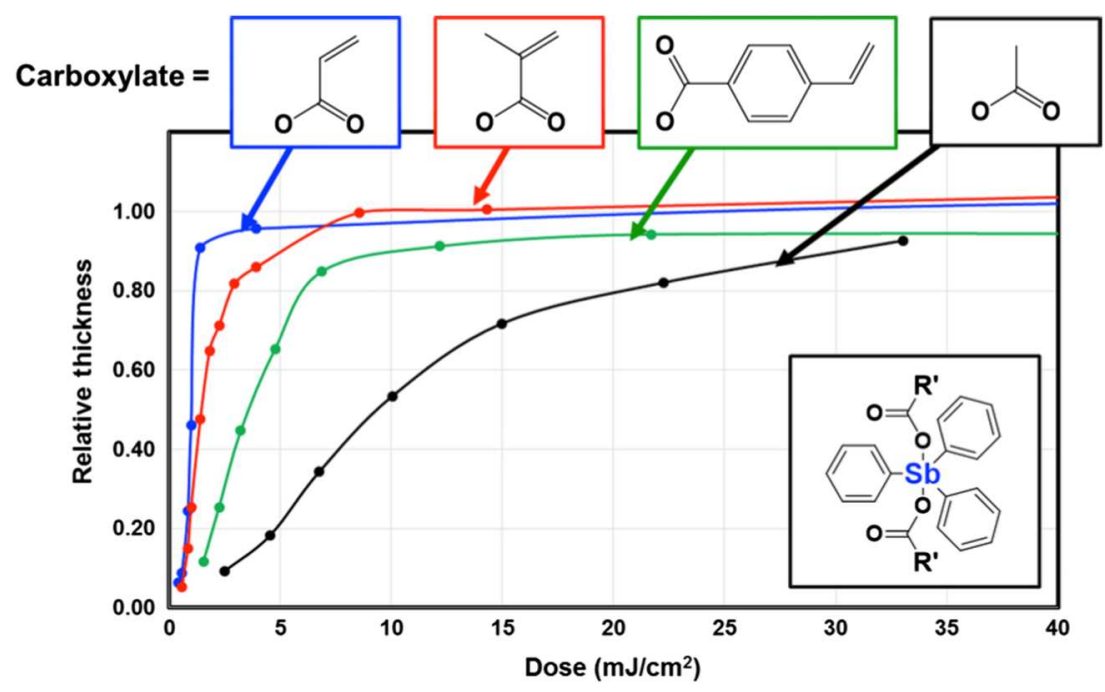

Fig. 5 Comparison of the sensitivity of $\mathrm{Ph}_{3} \mathrm{Sb}\left(\mathrm{O}_{2} \mathrm{CR}^{\prime}\right)_{2}$, where the carboxylate is acrylate, methacrylate, styrenecarboxylate, or acetate. Acrylate shows the best sensitivity of the four carboxylates evaluated.
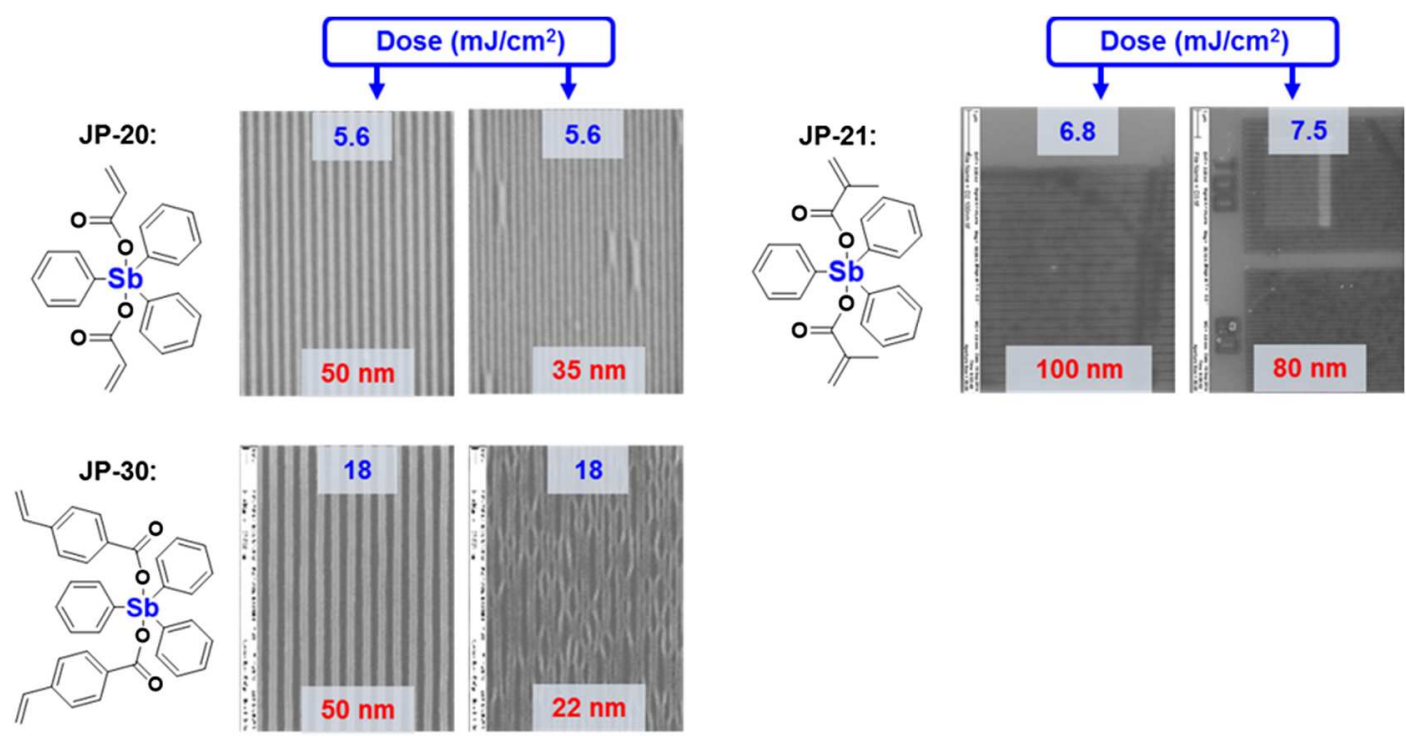

Fig. 6 Lithographic evaluation of three antimony organometallic carboxylates of the form $\mathrm{Ph}_{3} \mathrm{Sb}\left(\mathrm{O}_{2} \mathrm{CR}^{\prime}\right)_{2}$. High sensitivity at moderate resolution was demonstrated by JP-20 and good resolution at moderate sensitivity was demonstrated by JP-30.

in the second. We speculate that the resist material either ablates or melts due to electron beam energy.

While studying the effect of $\mathrm{R}$ and $\mathrm{O}_{2} \mathrm{CR}^{\prime}$ groups on resist performance, we observed that higher molecular weight groups yield improvements in SEM stability. Higher molecular weight $\mathrm{R}$ and $\mathrm{O}_{2} \mathrm{CR}^{\prime}$ groups should have lower volatility than the $\mathrm{R}$ and $\mathrm{O}_{2} \mathrm{CR}^{\prime}$ groups of JP-20. The best resolution images are shown for four resists (Fig. 9). Although not directly shown in the figure, these resists are in order of improving SEM stability.

In some ways, this SEM instability problem is similar to line-slimming observed in the early days of positive-tone 193-nm lithography 13 However, the SEM instability described here involves negative-tone resists and is most pronounced for our fastest resists. This is somewhat surprising because we would expect our fastest resists to be highly cross-linked and, therefore, less prone to evaporation or melting in the SEM. This is an active area of research by our group.

\subsubsection{Effect of hydrocarbon $(R)$ identity on sensitivity-unexpected results for $R=$ cyclohexyl or styrene}

$\mathbf{R}=\mathbf{C y c l o h e x y l}$. Figure 10 shows a direct comparison of phenyl and cyclohexyl on the lithographic performance of $\mathrm{R}_{3} \mathrm{Sb}\left(\mathrm{O}_{2} \mathrm{CR}^{\prime}\right)_{2}$ resists. Note that tricyclohexylantimony diacrylate (JP-38) shows a lithographic performance that is nearly identical to that of JP-20. This was surprising because of the potential differences in R-Sb bond characteristics for these two molecules. The similarities between these two molecules occur in the composition of the carboxylate group 

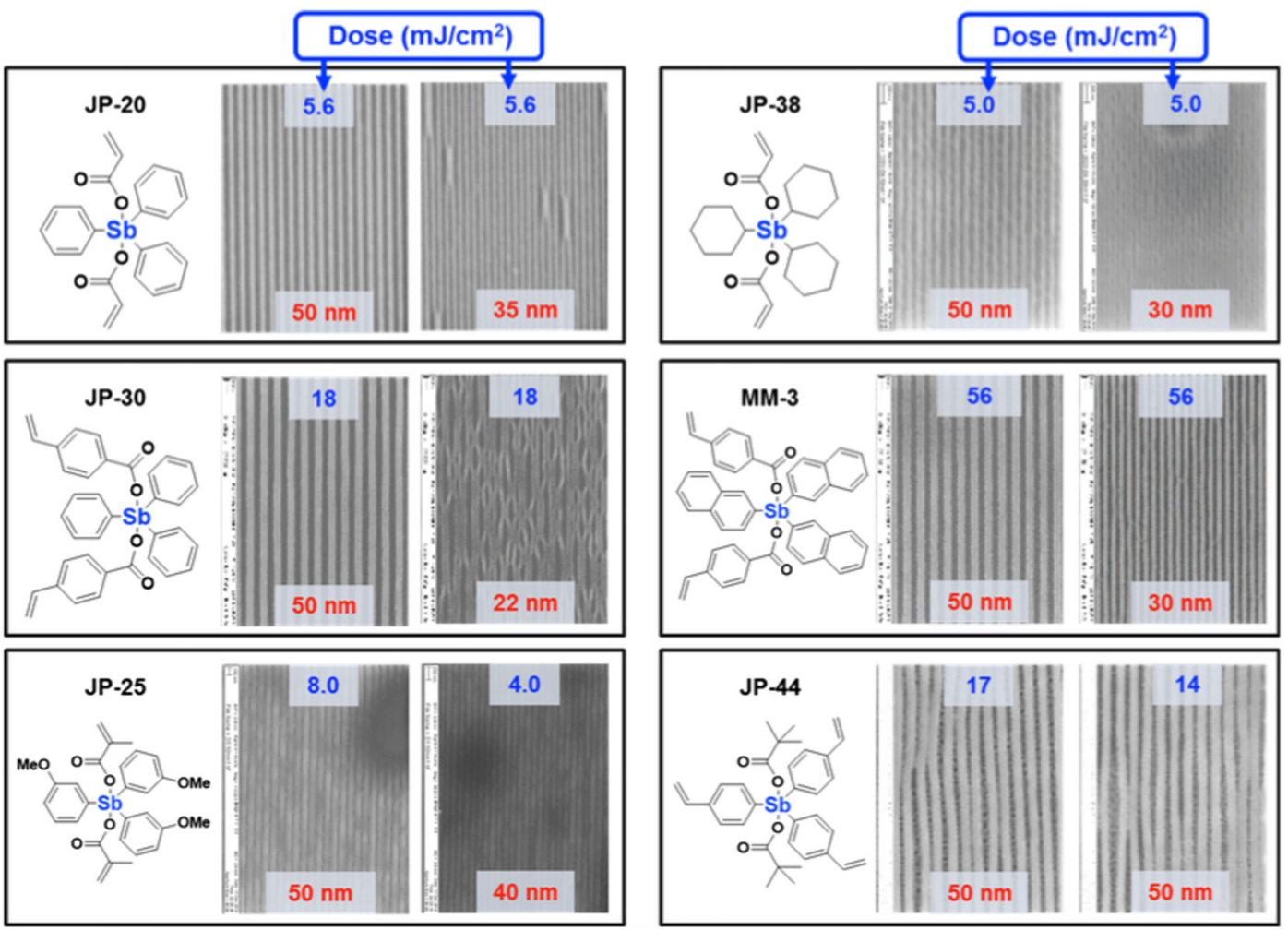

Fig. 7 Lithographic summary of six resists with five different $\mathrm{R}$ compositions. All resists attain good sensitivity. Pattern collapse is the current limit to high-resolution imaging.
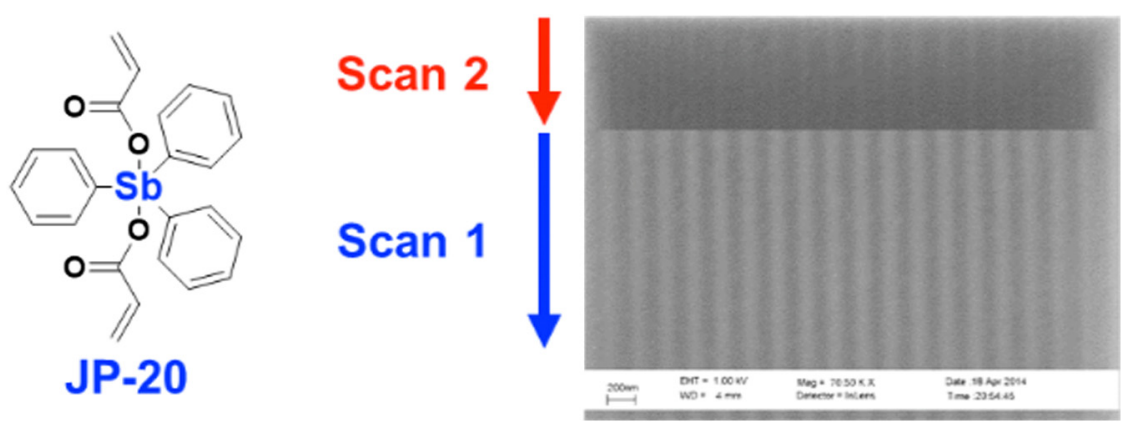

Fig. 8 SEM instability of JP-20. Pattern modulation is displayed in during the first scan of the electron beam. Pattern modulation is not observed during the second. We propose that the resist material is ablated due to electron beam energy or the pattern is melted.

and both $\mathrm{R}$ groups are six-carbon cycles. This may point to the role of the $\mathrm{R}$ group.

$\mathbf{R}=$ Styrene. In order to increase the density of polymerizable olefins in the resist films, we studied $\mathrm{R}$ groups with polymerizable olefins, such as styrene (Fig. 111). We synthesized tristyreneantimony diacrylate (LD-1). After exposure and development of LD-1 using our standard developer (hexane $30 \mathrm{~s}$ ), little change was observed in the unexposed region. After very aggressive development (dichloromethane $30 \mathrm{~s}$ ), material still remained in the unexposed region. Both development conditions readily clear the unexposed regions of an unexposed wafer. As a result, it appears that a change in solubility occurs in the unexposed regions of LD-1 as a result of the exposure process. Our current hypothesis is that (1) polymerization extended beyond the exposed regions into the unexposed regions and/or
(2) the resist is so sensitive that a solubility switch was produced by flare in the exposure chamber. If correct, this phenomena likely results from the high density of polymerizable olefins in a film of LD-1. In this way, once a polymerization event is initiated, it may propagate on a macroscopic length scale before termination. The two unanticipated results given in this section are explored in more detail in Sec. 2.4.

\subsection{Interpretation of Results}

The antimony organometallic carboxylate resists demonstrate a considerable departure from traditional polymeric resists. Traditional chemically amplified resists obtain good sensitivity through acid-catalyzed reactions. We propose that antimony organometallic carboxylate resists achieve good sensitivity through the inclusion of polymerizable olefins. In 


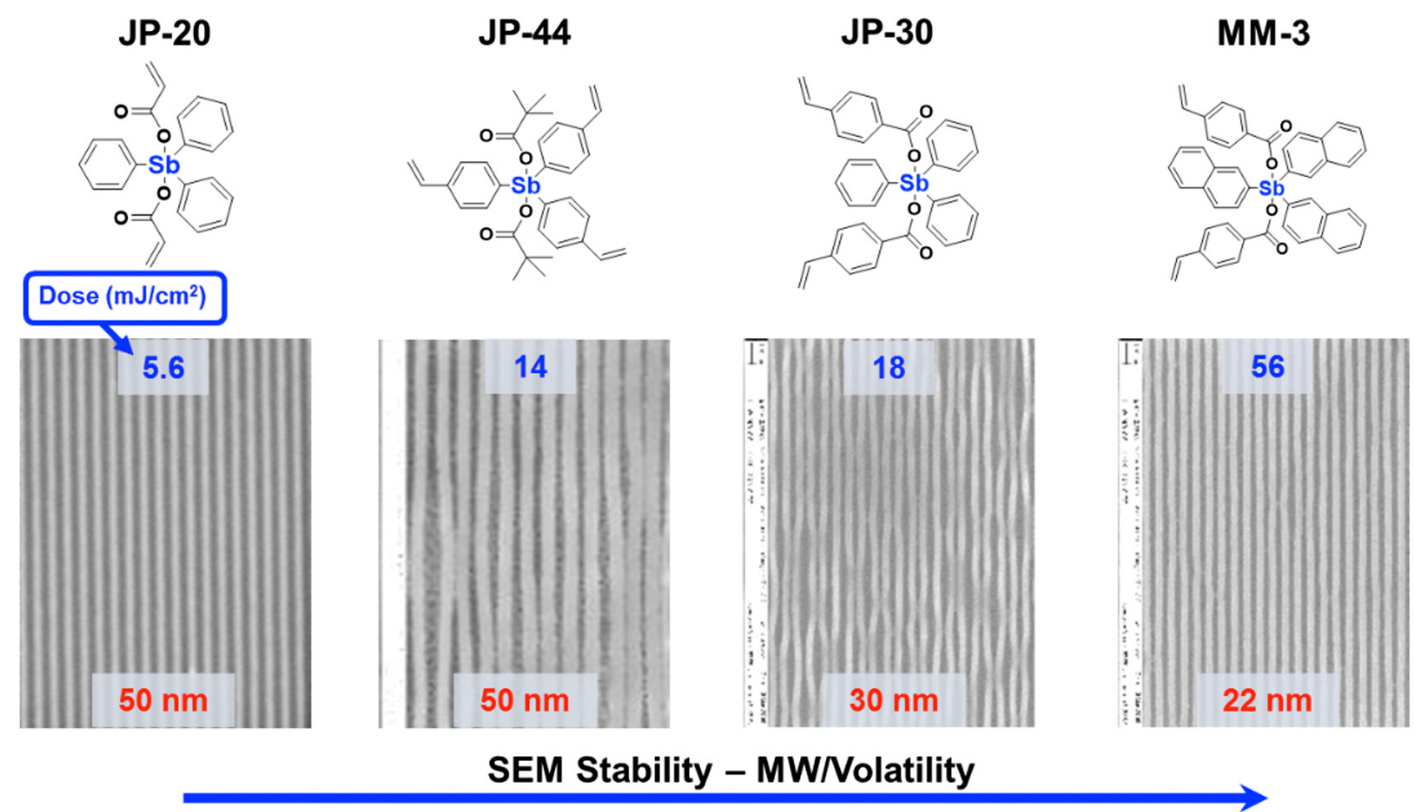

Fig. 9 SEM stability of antimony organometallic carboxylate molecules appears to improve with increases in molecular weight of the $\mathrm{R}$ and $\mathrm{O}_{2} \mathrm{CR}^{\prime}$ groups. There is a tradeoff with sensitivity.

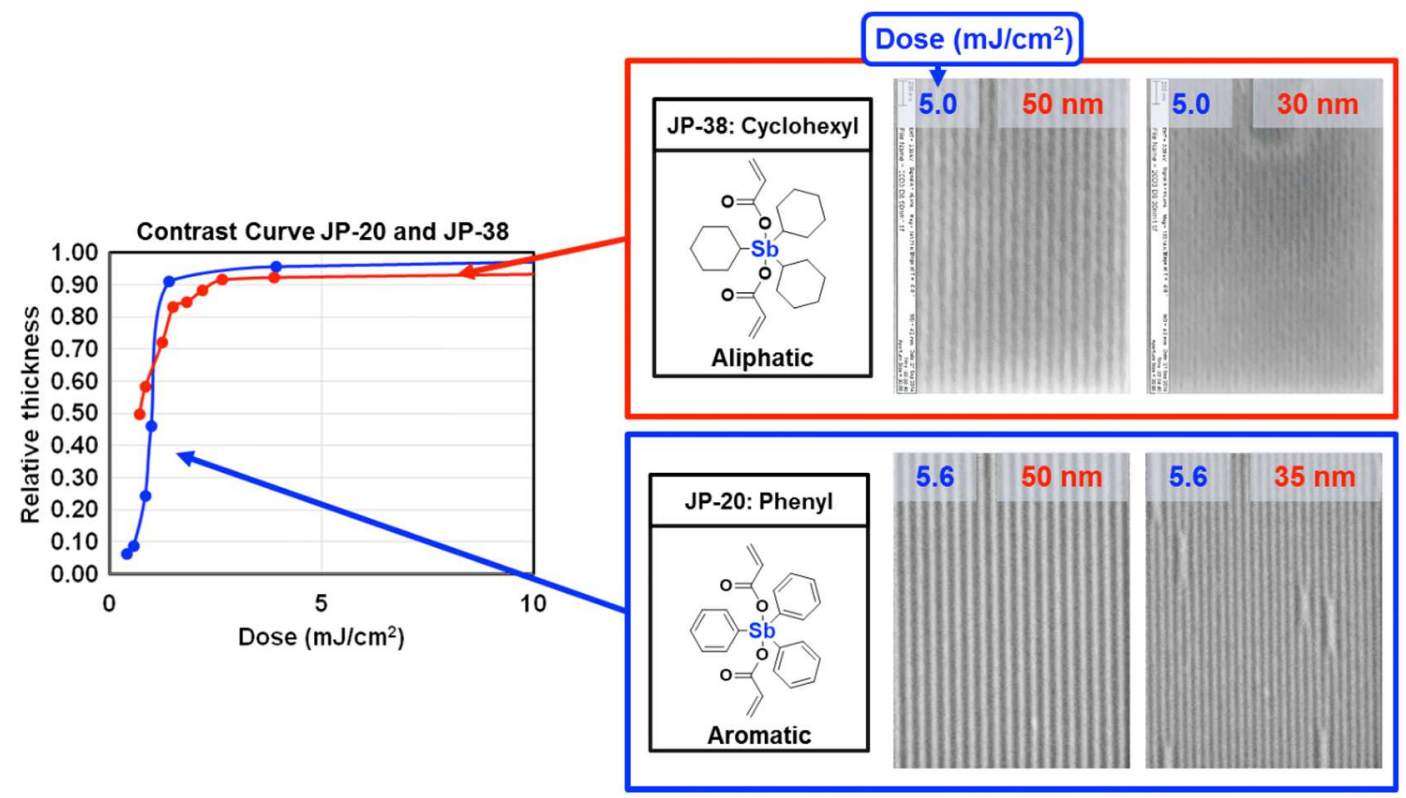

Fig. 10 Lithographic results of $R=$ cyclohexyl. Notice that this molecule displays very similar sensitivity and lithographic results as JP-20.

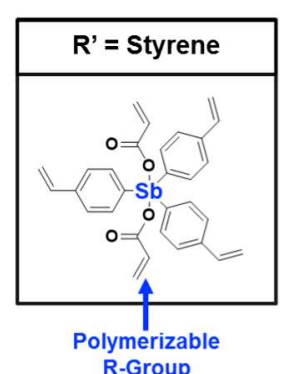

R-Group

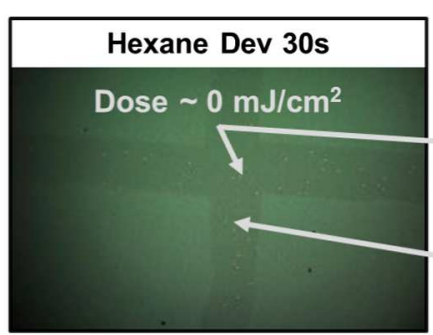

Normal Development

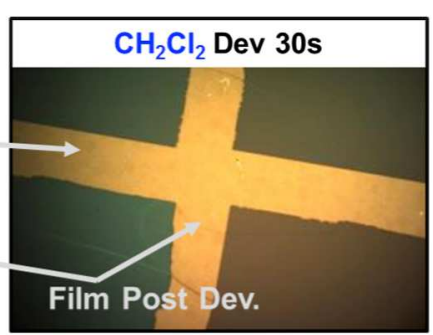

Very Aggressive Development

Fig. 11 Tristyreneantimony diacrylate (LD-1) has a high density of polymerizable olefins. A solubility shift occurs in the unexposed regions of an exposed wafer. This may be evidence of uncontrolled polymerization propagating to unexposed regions. 


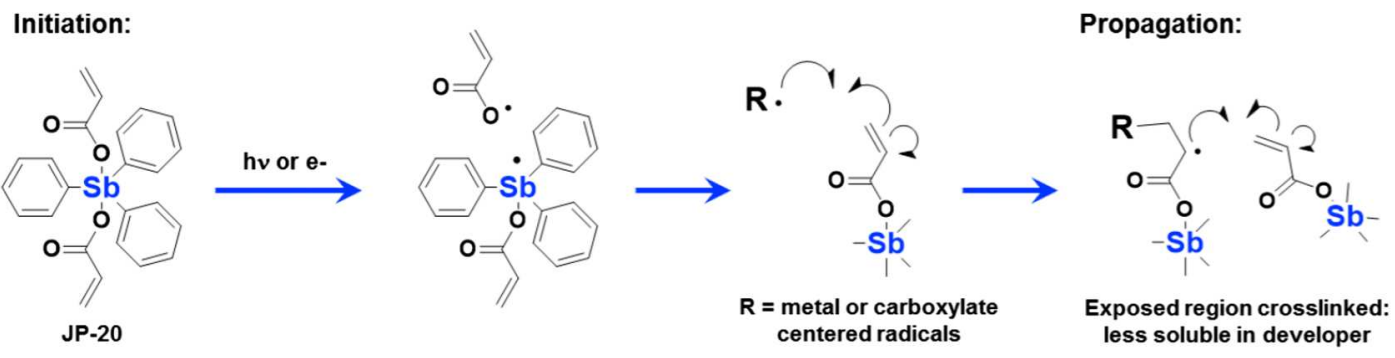

Fig. 12 Proposed mechanism of antimony organometallic carboxylate resist system. We propose that good sensitivity is achieved through one photochemical homolysis event leading to a cascade of subsequent solubility changing polymerization reactions.
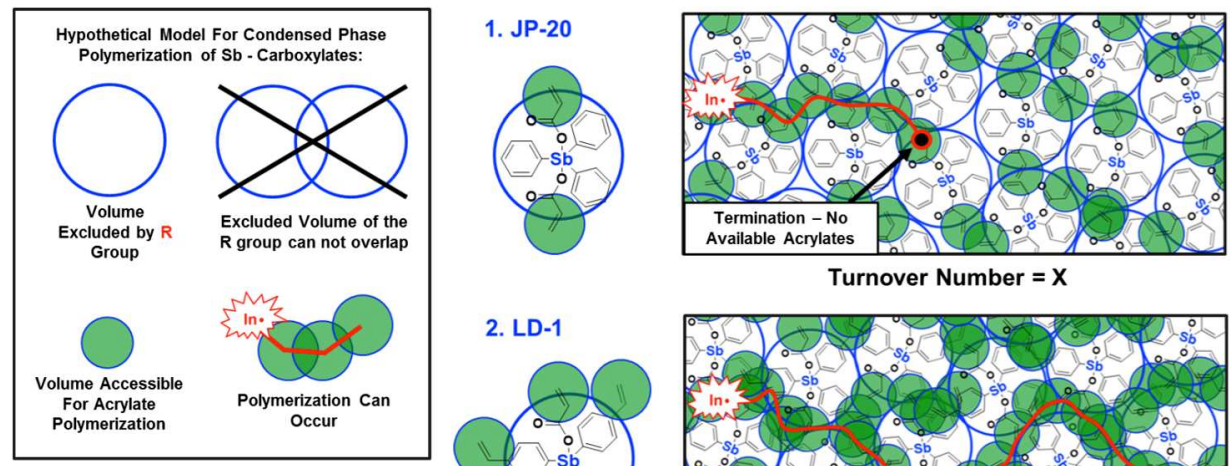

Turnover Number $=\mathbf{X}$
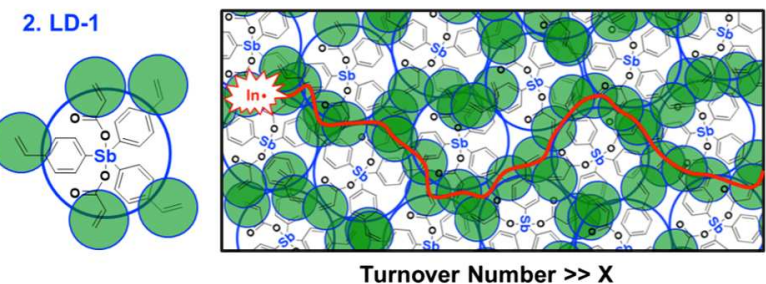

Fig. 13 Proposed model for condensed phase polymerization of antimony organometallic carboxylate resists.

this way, one initiation event may result in the polymerization of multiple olefins and thus multiple solubility changing events (Fig. 12). Given the revolutionary nature of this resist system, we must investigate the sensitivity mechanisms in order to understand the capabilities of the system and better target synthesis of new molecules.

$$
\mathrm{POL}=\frac{\# \text { of Polymerizable Olefins }}{\# \text { of Atoms (Excluding Hydrogen) }} \times 100 \%
$$

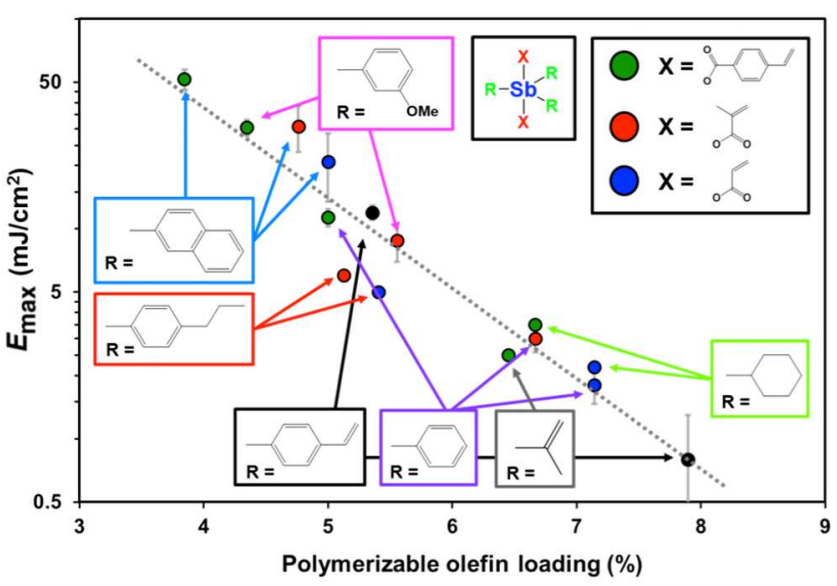

Fig. 14 Plot of $E_{\max }$ versus polymerizable olefin loading (POL). A linear trend is demonstrated between log $E_{\max }$ versus POL for multiple antimony organometallic carboxylates.
In Sec. 2.3.2, we detailed two surprising results. The first is that triphenylantimony diacrylate (JP-20) and tricyclohexylantimony diacrylate (JP-38) display similar lithographic performances (Fig. 10) despite the antimony-aromatic bond of JP-20 and the antimony-aliphatic bond of JP-38. What is similar between these two molecules is the ratio of the number of polymerizable olefins to the space filling $R$ groups. The second surprising result was observed for tristyreneantimony diacrylate (LD-1), which has a high density of polymerizable olefins as compared to space filling $R$ groups. This resist demonstrated an uncontrolled characteristic where full film thickness was observed in the unexposed region after standard development conditions $\left(E_{\max } \sim 0 \mathrm{~mJ} / \mathrm{cm}^{2}\right)$ (Fig. 11).

From these two surprising results, we can develop the hypothesis that the greatest contributor to the sensitivity of molecules of the type $\mathrm{R}_{n} \mathrm{Sb}\left(\mathrm{O}_{2} \mathrm{CR}^{\prime}\right)_{2}$ is the ratio of polymerizable olefins to space filling $\mathrm{R}$ groups. In order to further explore our sensitivity hypothesis, we have defined a hypothetical model for the condensed phase polymerization of $\mathrm{R}_{n} \mathrm{M}\left(\mathrm{O}_{2} \mathrm{CR}^{\prime}\right)_{2}$ (Fig. [13). The $\mathrm{R}$ groups in this model act as space filling substituents that cannot be superimposed

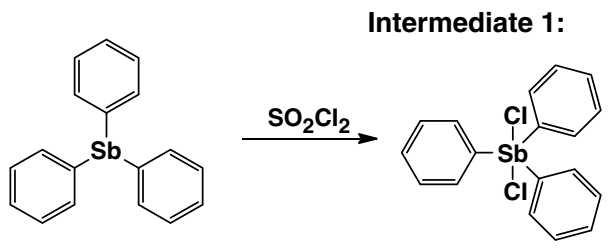

Fig. 15 Pathway $1-$ synthesis of intermediate $1\left(\mathrm{Ph}_{3} \mathrm{SbCl}_{2}\right)$. 


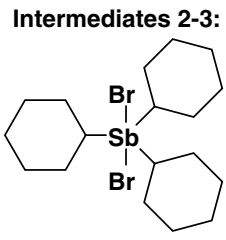

2

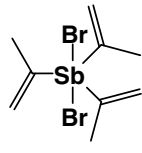

3
Synthetic path:

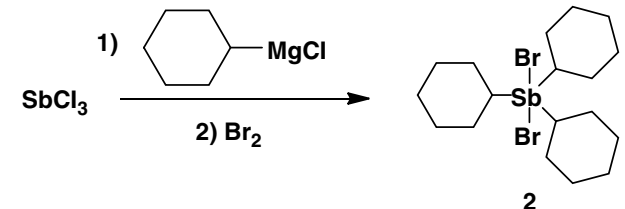

Fig. 16 Pathway 2-synthesis of intermediates 2 to 3.

Intermediates 4 - 7:

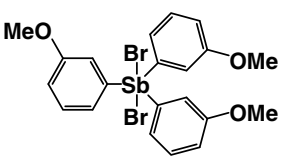

4

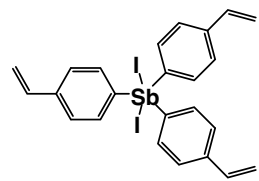

5

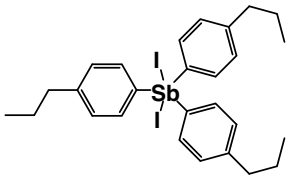

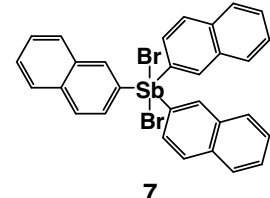

7

Fig. 17 Pathway 3-synthesis of Intermediates 4 to 7.

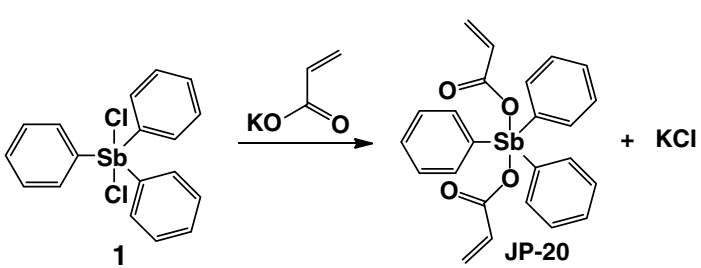

Fig. 18 Synthetic procedures for JP-20.

on other R groups. In order for the propagation of polymerization to occur, the reaction spheres of two polymerizable olefins must overlap. Our hypothesis states that the larger the ratio of polymerizable olefins to space filling $\mathrm{R}$ groups, the larger the turnover number of a given resist. A larger turnover number should lead to greater sensitivity because more molecules are reacted per initiation event, and because higher molecular weight molecules have lower solubility.

Our proposed sensitivity hypothesis suggests that the sensitivity of these resists should scale with polymerizable olefin loading (POL). A semilog plot of $E_{\max }$ versus POL is shown for multiple resist materials (Fig. 14). There is a linear relationship between $\log E_{\max }$ versus POL where as POL increases the $E_{\max }$ decreases (resist becomes more sensitive). On a linear scale, the trend approaches the $X$ axis at a POL of $\sim 9 \%$. This approach corresponds to a POL at which $E_{\max }$ is approaching $0 \mathrm{~mJ} / \mathrm{cm}^{2}$. This sensitivity is consistent with the uncontrolled characteristics of molecules like LD-1 $(\mathrm{POL}=14 \%)$.

Further investigation is underway in this area. Understanding of this mechanism should allow better targeting of molecules to improve the lithographic performance of these systems.

\section{Conclusions}

A novel resist system based on organometallic carboxylate molecules with polymerizable olefin substituents has been developed. This system has demonstrated exceptional sensitivity printing $35-\mathrm{nm}$ dense lines with $5.6 \mathrm{~mJ} / \mathrm{cm}^{2}$. We have studied over 35 molecules of the general form $\mathrm{R}_{n} \mathrm{M}\left(\mathrm{O}_{2} \mathrm{CR}^{\prime}\right)_{2}$ exibiting variations in $\mathrm{M}, \mathrm{R}$ and $\mathrm{O}_{2} \mathrm{CR}^{\prime}$. By comparing molecules of the type $\mathrm{Ph}_{n} \mathrm{M}$ (acrylate $)_{2}$, where $\mathbf{M}=$ antimony, bismuth, tin or tellurium, we found that antimony is the most sensitive and tellurium is the least. By comparing molecules of the type $\mathrm{Ph}_{3} \mathrm{Sb}\left(\mathrm{O}_{2} \mathrm{CR}^{\prime}\right)_{2}$, where the carboxylate is acrylate, methacrylate, styrenecarboxylate, or acetate, we found that polymerizable substituents are more sensitive than nonpolymerizable substituents and that sensitivity worsens with increasing carboxylate size. By comparing the sensitivities of molecules of the type $\mathrm{R}_{3} \mathrm{Sb}\left(\mathrm{O}_{2} \mathrm{CR}^{\prime}\right)_{2}$, we have developed the hypothesis that the size of the space filling $\mathrm{R}$ groups as compared to the number of polymerizable olefins contributes most greatly to the sensitivity. We have defined a POL, which mathematically relates the number of polymerizable olefins to the size of the $\mathrm{R}$ groups. We have observed that $\log E_{\max }$ versus POL is a linear relationship in which higher POL's lead to more sensitive resists. Our future work aims to (1) spectroscopically confirm the polymerization of olefins upon exposure to EUV and (2) measure the turnover number of resists as a function of POL.

\section{Experimental Methods}

\subsection{General}

All reactions were carried out under a nitrogen atmosphere. The reagent 4-chlorostyrene was purchased from Alfa Aesar. All other reagents were purchased from Sigma-Aldrich. All reagents were used as received unless otherwise specified.

\subsection{Instruments}

Nuclear magnetic resonance (NMR) spectra were obtained using a Bruker 400 spectrometer. All chemical shifts are reported as parts per million (ppm) relative to tetramethylsilane.

\subsection{General Resist Formulation and Imaging}

Resist formulations were made by dissolving solids in 1,2dichloroethane at $1.5 \mathrm{wt} \%$ solids and filtering through a $0.2-\mu \mathrm{m}$ polytetrafluoroethylene filter. Formulations were then spincast onto 4 -in. silicon wafers, coated with a crosslinked polymeric film (75\% hydroxyethyl methacrylate/25\% methyl methacrylate copolymers). Due to the low boiling point of dichloroethane, and somtimes poor thermal stability of organometallic antimony compounds, no post application bake or postexposure bake was utilized. Film thickness measurements are nontrivial for organometallic resist films with partial absorption in UV-Vis wavelengths. For select 
coatings, film thickness was studied with ellipsometry and profilometry. We found that the above resist formulations, when coated at $2000 \mathrm{rpm}$, generally resulted in 50- to 70$\mathrm{nm}$ film. Resist films were then exposed with $13.5-\mathrm{nm}$ radiation and developed using either deionized water (DI) water for 30 s (resists: JP-18, JP-20, JP-21, JP-38) or hexanes for $30 \mathrm{~s}$ (All Resists). In general, we utilize developers that can clear unexposed resist films in less than $5 \mathrm{~s}$. The resists in this study are relatively nonpolar due to their large hydrocarbon content. As a result, they are readily cleared with hexanes. In the case of molecules with relatively low hydrocarbon content, such as JP-18, 20, 21, and 38, the films can be cleared with DI water, although hexanes can clear these films faster than DI water and are thus a more aggressive developer for all of these resists. For molecules with greater hydrocarbon content such as JP-30 and JP-45, DI water cannot clear the resist film and hexanes must be utilized for $30 \mathrm{~s}$ at the developer. Two exposure tools were used for this study: the Berkeley direct contrast tool and the Paul-Scherrer Institut EUV interferometer

\subsection{Synthesis of Intermediates}

Antimony (V) intermediates are of the form $\left(\mathrm{R}_{3} \mathrm{SbX}_{2}\right)$, where $\mathrm{R}=$ an aromatic or aliphatic hydrocarbon and $\mathrm{X}=$ halide. Intermediates were synthesized using three different pathways. These pathways are outlined below.

\subsubsection{Pathway 1-synthesis of intermediate 1 $\left(\mathrm{Ph}_{3} \mathrm{SbCl}\right)_{2}$}

To a solution of triphenylantimony $(3.5 \mathrm{~g}, 10 \mathrm{mmol})$ in $200 \mathrm{ml}$ of hexane, sulfuryl chloride $(1.5 \mathrm{~g}, 11 \mathrm{mmol})$ was added dropwise (Fig. 15). A constant flow of nitrogen was kept through the reaction vessel to remove $\mathrm{SO}_{2}$ gas. After addition of sulfuryl chloride was complete, the reaction was stirred for $30 \mathrm{~min}$. The resulting white precipitate was collected by filtration and washed with $100 \mathrm{ml}$ hexane and dried in vacuum. $\mathrm{SbPh}_{3} \mathrm{Cl}_{2}:{ }^{1} \mathrm{H}$ NMR (400 $\mathrm{MHz}$, Chloroform-d) $\delta 8.32$ to 8.08 (m, 6H), 7.72 to 7.38 (m, 9H).

\subsubsection{Pathway 2-synthesis of intermediates 2 to 3}

Synthesis of intermediate 2-tricyclohexylantimony dibromide: To a stirring solution of antimony trichloride $(2.3 \mathrm{~g}, 10 \mathrm{mmol})$ in $50 \mathrm{ml}$ of anhydrous $\mathrm{Et}_{2} \mathrm{O}$ at $0^{\circ} \mathrm{C}, 2 \mathrm{M}$ cyclohexylmagnesium chloride $(16.5 \mathrm{ml}, 33 \mathrm{mmol})$ was added dropwise over the course of $30 \mathrm{~min}$ (Fig. 16). The reaction was allowed to warm to room temperature and stirred for an additional $2 \mathrm{~h}$. The reaction vessel was then cooled to $0^{\circ} \mathrm{C}$. Bromine $(1.6 \mathrm{~g}, 10 \mathrm{mmol})$ was then added dropwise to the stirring suspension over the course of $30 \mathrm{~min}$. After the addition of bromine, methanol $(50 \mathrm{ml})$ was used to quench the reaction while the flask was maintained at $0^{\circ} \mathrm{C}$. The resulting slurry was dried and extracted three times using ethyl acetate. Combined extracts were filtered through celite and reduced in volume. The concentrated extracts were crystalized overnight at $-10^{\circ} \mathrm{C}$. ${ }^{1} \mathrm{H}$ NMR (400 MHz, Chloroform-d) $\delta 3.32$ (tt, $\mathrm{J}=12.7,3.6 \mathrm{~Hz}, 1 \mathrm{H}$ ), $3.22(\mathrm{tt}, \mathrm{J}=12.7,3.6 \mathrm{~Hz}, 2 \mathrm{H}), 2.18$ to $2.08(\mathrm{~m}, 6 \mathrm{H}), 2.08$ to $1.91(\mathrm{~m}, 6 \mathrm{H}), 1.86$ to $1.72(\mathrm{~m}, 6 \mathrm{H}), 1.69$ to $1.46(\mathrm{~m}, 3 \mathrm{H})$, 1.46 to 1.17 (m, 9H).

Synthesis of intermediate 3-tri-isopropenylantimony dibromide: Intermediate $\mathbf{3}$ was synthesized in the same manner as intermediate 2 except isopropenylmagnesium bromide was substituted for cyclohexylmagnesium chloride. ${ }^{1} \mathrm{H}$ NMR (400 MHz, Chloroform-d) $\delta 5.71(\mathrm{~d}, \mathrm{~J}=47.3 \mathrm{~Hz}$, $6 \mathrm{H}), 2.43(\mathrm{~s}, 9 \mathrm{H})$.

\subsubsection{Pathway 3-synthesis of intermediates 4 to 7}

These molecules were synthesized from the corresponding aromatic Grignard and antimony trichloride in a similar fashion to intermediates $\mathbf{2}$ to $\mathbf{3}$ (Fig. 17). The substituted-triphenylantimony was collected and purified by crystallization. The substituted triphenylantimony was then oxidized by one equivalent of either elemental bromine or iodine to form intermediates 4 to 7 .

Tri-3-methoxyphenylantimony dibromide (4). ${ }^{1} \mathrm{H}$ NMR (400 MHz, Chloroform-d) $\delta 7.33$ to 7.17 (m, 3H), 7.05 to $6.93(\mathrm{~m}, 6 \mathrm{H}), 6.88$ to $6.80(\mathrm{~m}, 3 \mathrm{H}), 3.70(\mathrm{~s}, 9 \mathrm{H})$.

Tri-styreneantimony diiodide (5). ${ }^{1} \mathrm{H}$ NMR (400 MHz, Chloroform-d) $\delta 8.13$ to $7.85(\mathrm{~m}, 6 \mathrm{H}), 7.73$ to $7.36(\mathrm{~m}, 6 \mathrm{H})$, $6.73(\mathrm{dd}, \mathrm{J}=17.6,10.9 \mathrm{~Hz}, 3 \mathrm{H}), 5.83(\mathrm{~d}, \mathrm{~J}=17.6 \mathrm{~Hz}, 3 \mathrm{H})$, $5.39(\mathrm{~d}, \mathrm{~J}=10.9 \mathrm{~Hz}, 3 \mathrm{H})$.

Tri-4-propylantimony diiodide (6). ${ }^{1} \mathrm{H}$ NMR (400 MHz, Chloroform-d) $\delta 8.27$ to $7.80(\mathrm{~m}, 6 \mathrm{H}), 7.52$ to $7.15(\mathrm{~m}, 6 \mathrm{H})$, $2.63(\mathrm{t}, \mathrm{J}=7.7 \mathrm{~Hz}, 6 \mathrm{H}), 1.67(\mathrm{~h}, \mathrm{~J}=7.4 \mathrm{~Hz}, 6 \mathrm{H}), 0.97$ (t, J = 7.3 Hz, 9H).

Tri-napthylantimony dibromide (7). ${ }^{1} \mathrm{H} \quad$ NMR (400 MHz, Chloroform-d) $\delta 8.65$ (s, 3H), 8.19 (dd, J = 8.6, $1.7 \mathrm{~Hz}, 3 \mathrm{H}), 8.07$ to $7.83(\mathrm{~m}, 9 \mathrm{H}), 7.71$ to $7.50(\mathrm{~m}, 6 \mathrm{H})$.

\subsection{Synthesis of Carboxylate Substituted $\mathrm{R}_{3} \mathrm{Sb}\left(\mathrm{O}_{2} \mathrm{CR}^{\prime}\right)_{2}$}

Molecules of the type $\mathrm{R}_{3} \mathrm{SbX}_{2}$, where $\mathrm{X}=$ chloride, bromide, or iodide were reacted with carboxylate salts to form the desired $\mathrm{R}_{3} \mathrm{Sb}\left(\mathrm{O}_{2} \mathrm{CR}^{\prime}\right)_{2}$ product. Synthetic procedures for JP-20 are given below.

Synthesis of JP-20- $\mathrm{Ph}_{3} \mathrm{SbO}_{2} \mathrm{CR}_{2}^{\prime}\left(\mathrm{O}_{2} \mathrm{CR}^{\prime}=\right.$ Acrylate $)$ : A suspension of $1(3.8 \mathrm{~g}, 9 \mathrm{mmol})$ and potassium acrylate (4 g, $36 \mathrm{mmol}$ ) in $300 \mathrm{ml}$ of dichloromethane was stirred under nitrogen for $16 \mathrm{~h}$ (Fig. 18). The reaction mixture was filtered through celite and the residual solid washed with $100 \mathrm{ml}$ of dichloromethane. The filtrate and washings were collected and the dichloromethane evaporated. The resulting solid was dried in vacuum. ${ }^{1} \mathrm{H}$ NMR $(400 \mathrm{MHz}$, Chloroformd) $\delta 8.12$ to $7.85(\mathrm{~m}, 6 \mathrm{H}), 7.60$ to $7.34(\mathrm{~m}, 9 \mathrm{H}), 6.12(\mathrm{dd}$, $\mathrm{J}=17.3,2.0 \mathrm{~Hz}, 2 \mathrm{H}), 5.93(\mathrm{dd}, \mathrm{J}=17.3,10.2 \mathrm{~Hz}, 2 \mathrm{H}), 5.57$ (dd, $\mathrm{J}=10.2,2.0 \mathrm{~Hz}, 2 \mathrm{H})$.

Conversion of intermediates $\mathbf{2}$ to $\mathbf{7}$ to the desired $\mathrm{Ph}_{3} \mathrm{SbO}_{2} \mathrm{CR}_{2}^{\prime}$ followed the same synthetic procedures as conversion of intermediate 1 to JP-20. In these cases, the appropriate carboxylate salt (potassium acrylate, potassium methacrylate, or potassium styrenecarboxylate) is utilized in conjunction with the appropriate $\mathrm{R}_{3} \mathrm{SbX}_{2}$. If oil was obtained after removal of dichloromethane, the residue was then crystalized overnight from ethyl acetate at $-10^{\circ} \mathrm{C}$. NMR data are presented below.

Tri-phenylantimony diacetate (JP-18). ${ }^{1} \mathrm{H} \quad$ NMR (400 MHz, Chloroform-d) $\delta 8.25$ to 7.81 (m, 6H), 7.60 to $7.36(\mathrm{~m}, 9 \mathrm{H}), 1.80(\mathrm{~s}, 6 \mathrm{H})$.

Tri-phenylantimony dimethacrylate (JP-21). ${ }^{1} \mathrm{H}$ NMR (400 MHz, Chloroform-d) $\delta 8.06$ to 7.91 (m, 6H), 7.49 to $7.35(\mathrm{~m}, 9 \mathrm{H}), 5.88(\mathrm{~s}, 2 \mathrm{H}), 5.31(\mathrm{~s}, 2 \mathrm{H}), 1.73(\mathrm{~s}, 6 \mathrm{H})$.

Tri-3-methoyphenylantimony dimethacrylate (JP-25). ${ }^{1} \mathrm{H}$ NMR (400 MHz, Chloroform-d) $\delta 7.65$ to 7.56 (m, 3H), 
7.56 to $7.48(\mathrm{~m}, 3 \mathrm{H}), 7.35(\mathrm{t}, \mathrm{J}=8.0 \mathrm{~Hz}, 3 \mathrm{H}), 7.08$ to 6.91 $(\mathrm{m}, 3 \mathrm{H}), 5.98$ to $5.86(\mathrm{~m}, 2 \mathrm{H}), 5.35(\mathrm{~s}, 2 \mathrm{H}), 3.78(\mathrm{~s}, 9 \mathrm{H}), 1.78$ (s, 6H).

Tri-phenylantimony distyrenecarboxylate (JP-30). ${ }^{1} \mathrm{H}$ NMR (400 MHz, Chloroform-d) $\delta 8.14$ to 8.04 (m, $6 \mathrm{H}), 7.86(\mathrm{~d}, \mathrm{~J}=8.2 \mathrm{~Hz}, 4 \mathrm{H}), 7.51$ to $7.40(\mathrm{~m}, 9 \mathrm{H}), 7.33$ $(\mathrm{d}, \mathrm{J}=8.1 \mathrm{~Hz}, 4 \mathrm{H}), 6.67(\mathrm{dd}, \mathrm{J}=17.6,10.9 \mathrm{~Hz}, 2 \mathrm{H})$, $5.75(\mathrm{~d}, \mathrm{~J}=17.6 \mathrm{~Hz}, 2 \mathrm{H}), 5.26(\mathrm{~d}, 2 \mathrm{H})$.

Tri-isopropenylantimony distyrenecarboxylate (JP-33). ${ }^{1} \mathrm{H}$ NMR (400 MHz, Chloroform-d) $\delta 7.93$ (d, 4H), 7.40 $(\mathrm{d}, 4 \mathrm{H}), 6.72(\mathrm{dd}, \mathrm{J}=17.6,10.9 \mathrm{~Hz}, 2 \mathrm{H}), 5.89$ to 5.67 $(\mathrm{m}, 8 \mathrm{H}), 5.31(\mathrm{~d}, 2 \mathrm{H}), 2.38(\mathrm{~s}, 9 \mathrm{H})$.

Tri-cyclohexylantimony diacrylate (JP-38). ${ }^{1} \mathrm{H}$ NMR (400 MHz, Chloroform-d) $\delta 6.21$ (dd, J = 17.3, $2.2 \mathrm{~Hz}$, 2H), $6.08(\mathrm{dd}, 2 \mathrm{H}), 5.66(\mathrm{dd}, \mathrm{J}=9.9,2.2 \mathrm{~Hz}, 2 \mathrm{H}), 3.10$ (tt, $\mathrm{J}=12.7,3.3 \mathrm{~Hz}, 3 \mathrm{H}), 2.19$ to $2.04(\mathrm{~m}, 6 \mathrm{H}), 1.99$ to $1.82(\mathrm{~m}, 6 \mathrm{H}), 1.82$ to $1.65(\mathrm{~m}, 6 \mathrm{H}), 1.65$ to $1.46(\mathrm{~m}, 3 \mathrm{H})$, 1.39 to $1.14(\mathrm{~m}, 9 \mathrm{H})$.

Tri-styreneantimony bis-diphenylacetate (JP-40). ${ }^{1} \mathrm{H}$ NMR (400 MHz, Chloroform-d) $\delta 7.66(\mathrm{~d}, 6 \mathrm{H}), 7.33$ $(\mathrm{d}, 6 \mathrm{H}), 7.16$ to $7.08(\mathrm{~m}, 12 \mathrm{H}), 6.97$ to $6.90(\mathrm{~m}, 8 \mathrm{H})$, $6.70(\mathrm{dd}, \mathrm{J}=17.6,10.9 \mathrm{~Hz}, 3 \mathrm{H}), 5.80(\mathrm{~d}, \mathrm{~J}=17.6 \mathrm{~Hz}, 3 \mathrm{H})$, $5.34(\mathrm{~d}, \mathrm{~J}=10.9 \mathrm{~Hz}, 3 \mathrm{H}), 4.80(\mathrm{~s}, 2 \mathrm{H})$.

Tri-napthylantimony diacrylate (JP-42). ${ }^{1} \mathrm{H} \quad \mathrm{NMR}$ (400 MHz, Chloroform-d) $\delta 8.57(\mathrm{~s}, 3 \mathrm{H}), 8.17(\mathrm{dd}, \mathrm{J}=8.6$, $1.5 \mathrm{~Hz}, 3 \mathrm{H}), 7.96(\mathrm{~d}, \mathrm{~J}=8.6 \mathrm{~Hz}, 3 \mathrm{H}), 7.91$ to $7.82(\mathrm{~m}, 6 \mathrm{H})$, 7.61 to $7.49(\mathrm{~m}, 6 \mathrm{H}), 6.16(\mathrm{dd}, \mathrm{J}=17.3,1.9 \mathrm{~Hz}, 2 \mathrm{H}), 5.96$ $(\mathrm{dd}, \mathrm{J}=17.2,10.1 \mathrm{~Hz}, 2 \mathrm{H}), 5.58(\mathrm{dd}, \mathrm{J}=10.2,1.9 \mathrm{~Hz}, 2 \mathrm{H})$.

Tri-napthylantimony dimethacrylate (JP-43). ${ }^{1} \mathrm{H}$ NMR (400 MHz, Chloroform-d) $\delta 8.58(\mathrm{~s}, 3 \mathrm{H}), 8.16(\mathrm{dd}, \mathrm{J}=8.6$, $1.4 \mathrm{~Hz}, 3 \mathrm{H}), 7.95(\mathrm{~d}, \mathrm{~J}=8.6 \mathrm{~Hz}, 3 \mathrm{H}), 7.90$ to $7.82(\mathrm{~m}, 6 \mathrm{H})$, 7.58 to $7.46(\mathrm{~m}, 6 \mathrm{H}), 5.95(\mathrm{~s}, 2 \mathrm{H}), 5.32(\mathrm{~s}, 2 \mathrm{H}), 1.75(\mathrm{~s}, 6 \mathrm{H})$.

Tri-styreneantimony dipivalate (JP-44). ${ }^{1} \mathrm{H} \quad \mathrm{NMR}$ (400 MHz, Chloroform-d) $\delta 7.88(\mathrm{~d}, 6 \mathrm{H}), 7.44(\mathrm{~d}, 6 \mathrm{H})$, $6.69(\mathrm{dd}, \mathrm{J}=17.6,10.9 \mathrm{~Hz}, 3 \mathrm{H}), 5.79(\mathrm{dd}, \mathrm{J}=17.6$, $0.8 \mathrm{~Hz}, 3 \mathrm{H}), 5.30$ (dd, J = 10.9, $0.8 \mathrm{~Hz}, 3 \mathrm{H}), 0.95$ (s, 18H).

Tri-4-propylphenylantimony diacrylate (JP-45). ${ }^{1} \mathrm{H}$ NMR (400 MHz, Chloroform-d) $\delta 8.06$ to $7.79(\mathrm{~m}, 6 \mathrm{H})$, 7.29 to $7.03(\mathrm{~m}, 6 \mathrm{H}), 6.12(\mathrm{dd}, \mathrm{J}=17.3,2.0 \mathrm{~Hz}, 2 \mathrm{H})$, $5.95(\mathrm{dd}, \mathrm{J}=17.3,10.1 \mathrm{~Hz}, 2 \mathrm{H}), 5.57(\mathrm{dd}, \mathrm{J}=10.2,2.0 \mathrm{~Hz}$, 2H), 2.58 (t, 6H), $1.62(\mathrm{~h}, 6 \mathrm{H}), 0.92$ (t, J = 7.3 Hz, 9H).

Tri-4-propylphenylantimony dimethacrylate (JP-46). ${ }^{1} \mathrm{H}$ NMR (400 MHz, Chloroform-d) $\delta 7.88(\mathrm{~d}, 6 \mathrm{H}), 7.24$ $(\mathrm{d}, 6 \mathrm{H}), 5.88(\mathrm{~s}, 2 \mathrm{H}), 5.30(\mathrm{~s}, 2 \mathrm{H}), 2.58(\mathrm{t}, \mathrm{J}=8.6,6.8 \mathrm{~Hz}$, $6 \mathrm{H}), 1.75(\mathrm{~s}, 6 \mathrm{H}), 1.63(\mathrm{~h}, 6 \mathrm{H}), 0.92(\mathrm{t}, \mathrm{J}=7.4 \mathrm{~Hz}, 9 \mathrm{H})$.

Tri-napthylantimony distyrenecarboxylate (MM-3). ${ }^{1} \mathrm{H}$ NMR (400 MHz, Chloroform-d) $\delta 8.69$ (s, 3H), 8.26 $(\mathrm{d}, \mathrm{J}=8.6,1.1 \mathrm{~Hz}, 3 \mathrm{H}), 7.96(\mathrm{~d}, \mathrm{~J}=8.6 \mathrm{~Hz}, 3 \mathrm{H}), 7.91$ to $7.80(\mathrm{~m}, 10 \mathrm{H}), 7.64$ to $7.44(\mathrm{~m}, 6 \mathrm{H}), 7.32(\mathrm{~d}, \mathrm{~J}=8.1 \mathrm{~Hz}$, $4 \mathrm{H}), 6.66(\mathrm{dd}, \mathrm{J}=17.6,10.9 \mathrm{~Hz}, 2 \mathrm{H}), 5.74(\mathrm{~d}, \mathrm{~J}=17.6$ $\mathrm{Hz}, 2 \mathrm{H}), 5.35$ to $5.17(\mathrm{~m}, 2 \mathrm{H})$.

Tri-styreneantimony diacrylate (LD-1). ${ }^{1} \mathrm{H} \quad \mathrm{NMR}$ (400 MHz, Chloroform-d) $\delta 7.97$ to $7.88(\mathrm{~m}, 6 \mathrm{H}), 7.55$ to $7.42(\mathrm{~m}, 6 \mathrm{H}), 6.69(\mathrm{dd}, \mathrm{J}=17.6,10.9 \mathrm{~Hz}, 3 \mathrm{H}), 6.14$ (dd, $\mathrm{J}=17.2,1.9 \mathrm{~Hz}, 2 \mathrm{H}), 5.94(\mathrm{dd}, \mathrm{J}=17.3,10.1 \mathrm{~Hz}, 2 \mathrm{H})$, 5.79 (dd, J = 17.6, $0.8 \mathrm{~Hz}, 3 \mathrm{H}), 5.60$ (dd, J = 10.2, $1.9 \mathrm{~Hz}$, 2H), 5.32 (dd, J = 10.9, $0.8 \mathrm{~Hz}, 3 \mathrm{H})$.

\section{Acknowledgments}

We would like to thank Sematech for financial support of this work. We would like to thank DuPont for supplying us with ESCAP polymer and King Industries for supplying us with a thermal acid generator for organic underlayers. We would also like to thank Michaela Vockenhuber for providing assistance at the Paul Scherrer Institute. Finally, we would like to thank Patrick Naulleau at the Lawrence Berkeley National Laboratory for providing us with SuMMIT Lithography Image Analysis software. Part of this work was performed at Swiss Light Source, Switzerland.

\section{References}

1. G. Moore, "Cramming more components onto integrated circuits," Electronics 38(8), 114-117 (1965).

2. J. Paul et al., "Advanced dual hard mask patterning scheme to enable high resolution lithography for sub 30nm technology nodes," Electrochemical Society Abstract Program \# 2928 (2012).

3. J. Paul et al., "Advanced etch technology for nanopatterning II," Proc. SPIE 8685, 86850 (2013).

4. S. Kang et al., "Characterization of the photoacid diffusion length and reaction kinetics in EUV photoresists with IR spectroscopy," Macromolecules 43, 4275-4286 (2010).

5. G. P. Patsis, V. Constantoudis, and E. Gogolides, Microelectron. Eng. 75, 297-308 (2004)

6. Y. Ekinci et al., "Evaluation of EUV resist performance with interference lithography towards $11 \mathrm{~nm}$ half-pitch and beyond," Proc. SPIE 8679, 867910 (2013).

7. B. L. Henke, E. M. Gullikson, and J. C. Davis, "X-ray interactions: photoabsorption, scattering, transmission, and reflection at $\mathrm{E}=50$ 30000 eV, Z=1-92," At. Data Nucl. Data Tables 54(2), 181-342 (1993).

8. M. Koton and F. Florinskii, "Synthesis and polymerization of tris(pvinylphenyl)antimony and tris(p-vinyl)phenylbismuth," Dokl. Akad. Nauk SSSR 169(3), 598-599 (1966).

9. S. Blanksby and B. Ellison, "Bond dissociation energies of organic molecules," Acc. Chem. Res. 36(4), 255-263 (2003).

10. I. Haiduc and J. J. Zuckerman, Basic Organometallic Chemistry: Containing Comprehensive Bibliography, W. De Gruyter, Ed., Berlin (1985).

11. H. Suzuki, Organobismuth Chemistry, Elsevier Science, Amsterdam (2001).

12. R. Bach, P. Ayala, and H. Schlegel, "A reassessment of the bond dissociation energies of peroxides," ". Am. Chem. Soc. 118(50), 1275812765 (1996)

13. T. Kudo et al., "CD changes of $193 \mathrm{~nm}$ resists during SEM measurement," Proc. SPID 4345, 179 (2001).

James Passarelli was an undergraduate student at the State University of New York (SUNY) Polytechnic University at the time this work was completed. He graduated in May 2015 and is currently pursuing a $\mathrm{PhD}$ in material science at Northwestern University.

Michael Murphy is a graduate student at the SUNY Polytechnic Institute. He received his BS degree in nanoscale engineering from the College of Nanoscale Science and Engineering in 2014. He is currently pursuing a $\mathrm{PhD}$ in nanoscale engineering in the College of Nanoscale Science and Engineering investigating novel materials for use in EUV lithography.

Miriam Sortland graduated with a BS in nanotechnology from the University Of Bergen, Norway, in 2012. She was a graduate student at the College of Nanoscale Science and Engineering at the time this work was completed, and she finished her MS in nanoengineering here in 2015 . She is now pursuing a career in a non-scientific field.

Jodi Hotalen is a graduate student at the SUNY Polytechnic Institute. She received his BS degree in chemistry with minors in physics and math from Hartwick College in 2013. She is currently pursuing a PhD in nanoscience with a focus in nanolithography and organic synthesis at SUNY Polytechnic Institute.

Robert Brainard received his BS in chemistry from U.C. Berkeley in 1979. He studied the reaction mechanisms of organoplatinum compounds during his graduate studies with Professor G. Whitesides at MIT and Harvard University. Following his post-doctoral studies with Professor R. Madix at Stanford University, he worked for Polaroid and Shipley/RHEM in the areas of: DUV, EUV and ebeam photoresists. Currently, he is a professor at CNSE investigating new materials for use in EUV lithography.

Biographies for the other authors are not available. 